\title{
La percepción del cuerpo y la tecnología en el cuento de ciencia ficción La máquina de respirar de Juan Pablo Goñi Capurro.
}

The perception of the body and technology in the science fiction story The breathing machine by Juan Pablo Goñi Capurro.

DOI: 10.32870/sincronia.axxv.n79.21a21

\section{Carmina Alejandra García Serrano}

Departamento de Letras. Universidad de Guadalajara (MÉXICO)

CE: carminaburana74@hotmail.com / ID ORDID: 0000-0003-0333-7381

\section{Esta obra está bajo una Licencia Creative Commons Atribución-NoComercial 4.0 Internacional}

Recibido: 30/09/2020

Revisado: 03/10/2020

Aprobado: $10 / 11 / 2020$

\section{RESUMEN}

En el presente artículo se analiza el cuento de ciencia ficción llamado La máquina de respirar del autor Juan Pablo Goñi Capurro. La finalidad del artículo es determinar la forma en la que se presenta la nueva tecnología en comparación con la vieja tecnología, determinar cuál es su impacto a partir de la propuesta de Solivérez (2003). Además, se pretende explicar cuál es la percepción del cuerpo, las funciones del cuerpo y el cuerpo como máquina.

Palabras Clave: Cuerpo. Tecnología. Máquina. Percepción.

\section{ABSTRACT}

This article analyzes the science fiction story called La máquina de respirar by the author Juan Pablo Goñi Capurro. The purpose of the article is to determine the way in which the new technology is presented compared to the old technology, to determine what its impact is based on the proposal of 
Solivérez (2003). It is also intended to explain the perception of the body, the functions of the body and the body as a machine.

Keywords: Body. Technology. Machine. Perception.

\section{El uso e impacto de la nueva tecnología}

Conforme la ciencia y la tecnología avanzan, se van desarrollando nuevas herramientas mediante las que se puede optimizar una tarea de la vida cotidiana. Se agilizan procesos, se acortan tiempos, se facilitan tareas, entre otras, sin embargo, a cada adaptación de una tarea mediante el uso de la tecnología, se encuentran impactos negativos y positivos en el ambiente, la vida cotidiana, la economía, la política, la cultura, etc. Solivérez (2003, p. 24) menciona los siguientes impactos:

1. Impacto práctico: ¿Para qué sirve? ¿Qué permite hacer que sin ella sería imposible? ¿Qué facilita?

2. Impacto simbólico: ¿Qué simboliza o representa? ¿Qué connota?

3. Impacto tecnológico propiamente dicho: ¿Qué objetos o saberes técnicos preexistentes lo hacen posible? ¿Qué reemplaza o deja obsoleto? ¿Qué disminuye o hace menos probable? ¿Qué recupera o revaloriza? ¿Qué obstáculos al desarrollo de otras tecnologías elimina?

4. Impacto ambiental: ¿El uso de qué recursos aumenta, disminuye o reemplaza? ¿Qué residuos o emanaciones produce? ¿Qué efectos tiene sobre la vida animal y vegetal?

5. Impacto ético: ¿Qué necesidad humana básica permite satisfacer mejor? ¿Qué deseos genera o potencia? ¿Qué daños reversibles o irreversibles causa? ¿Qué alternativas más beneficiosas existen?

6. Impacto epistemológico: ¿Qué conocimientos previos cuestiona? ¿Qué nuevos campos de conocimiento abre o potencia? 
Tomando en cuenta esta propuesta, se puede desprender del uso de la nueva tecnología que aparece en el cuento los impactos que tiene en el contexto que se plantea, que es el siglo XXII. Las descripciones del cuento analizado no agotan todas las preguntas que se plantean con respecto al tipo de impacto, pero aparecen por lo menos una de cada tipo. A continuación, se muestran las nuevas tecnologías que se mencionan en el texto y sus impactos en el siglo XXII:

\section{Tabla 1. Impactos de la nueva tecnología.}

\begin{tabular}{|c|c|c|c|c|c|c|}
\hline Nueva tecnología & $\begin{array}{l}\text { Impacto } \\
\text { práctico }\end{array}$ & $\begin{array}{l}\text { Impacto } \\
\text { simbólico }\end{array}$ & $\begin{array}{c}\text { Impacto } \\
\text { tecnológico }\end{array}$ & $\begin{array}{l}\text { Impacto } \\
\text { ambiental }\end{array}$ & Impacto ético & $\begin{array}{c}\text { Impacto } \\
\text { epistemol } \\
\text { ógico }\end{array}$ \\
\hline Cortina de defensa & $\begin{array}{l}\text { Protege el } \\
\text { planeta de los } \\
\text { ataques de los } \\
\text { purpurados. }\end{array}$ & Protección & No se presenta. & $\begin{array}{l}\text { Aumenta } \\
\text { el uso de } \\
\text { energía. }\end{array}$ & $\begin{array}{l}\text { Satisface la } \\
\text { necesidad } \\
\text { protegerse de } \\
\text { ataques de } \\
\text { otros. }\end{array}$ & Física \\
\hline $\begin{array}{l}\text { Circulador de } \\
\text { moléculas }\end{array}$ & $\begin{array}{l}\text { Mantiene la } \\
\text { temperatura } \\
\text { interna de los } \\
\text { edificios. }\end{array}$ & Bienestar & $\begin{array}{l}\text { Reemplaza el aire } \\
\text { acondicionado }\end{array}$ & $\begin{array}{l}\text { Aumenta } \\
\text { el uso de } \\
\text { energía. }\end{array}$ & $\begin{array}{l}\text { Satisface la } \\
\text { necesidad de } \\
\text { tener las } \\
\text { condiciones } \\
\text { climáticas } \\
\text { adecuadas } \\
\text { para vivir. }\end{array}$ & Física \\
\hline $\begin{array}{l}\text { Activador de flujo } \\
\text { de neones }\end{array}$ & Genera luz. & $\begin{array}{l}\text { Visibilidad o } \\
\text { iluminación }\end{array}$ & $\begin{array}{l}\text { Remplaza } \\
\text { lámparas y focos. }\end{array}$ & $\begin{array}{l}\text { Aumenta } \\
\text { el uso de } \\
\text { energía. }\end{array}$ & $\begin{array}{l}\text { Satisface la } \\
\text { necesidad de } \\
\text { tener luz en } \\
\text { todo para ver } \\
\text { en todo } \\
\text { momento. }\end{array}$ & Física \\
\hline $\begin{array}{l}\text { Nuevas fuentes } \\
\text { energéticas: } \\
\text {-Flujo de neones. }\end{array}$ & $\begin{array}{l}\text { Es energía y } \\
\text { sirve para hacer } \\
\text { funcionar toda } \\
\text { la nueva }\end{array}$ & No se menciona & $\begin{array}{l}\text { Remplaza a la } \\
\text { electricidad. }\end{array}$ & $\begin{array}{l}\text { No se } \\
\text { menciona. }\end{array}$ & $\begin{array}{l}\text { Satisface las } \\
\text { necesidades } \\
\text { de consumo } \\
\text { energético. }\end{array}$ & Física \\
\hline
\end{tabular}




\begin{tabular}{|c|c|c|c|c|c|c|}
\hline & tecnología & & & & & \\
\hline $\begin{array}{l}\text { Servicio público de } \\
\text { teletransportación }\end{array}$ & $\begin{array}{l}\text { Sirve para } \\
\text { moverse más } \\
\text { rápidamente de } \\
\text { un lugar a otro. }\end{array}$ & $\begin{array}{l}\text { Movilidad } \\
\text { instantánea }\end{array}$ & $\begin{array}{l}\text { Remplaza la } \\
\text { acción de caminar } \\
\text { por largas } \\
\text { distancias, } \\
\text { transportadores, } \\
\text { transbordadores, } \\
\text { vehículos con } \\
\text { ruedas y aviones. }\end{array}$ & $\begin{array}{l}\text { Aumenta } \\
\text { el uso de } \\
\text { energía. }\end{array}$ & $\begin{array}{l}\text { Satisface la } \\
\text { necesidad de } \\
\text { transportarse } \\
\text { con rapidez. }\end{array}$ & Física \\
\hline $\begin{array}{l}\text { Nuevos } \\
\text { transportadores }\end{array}$ & $\begin{array}{l}\text { Sirve para } \\
\text { transportarse } \\
\text { de un lugar a } \\
\text { otro. }\end{array}$ & Movilidad rápida & $\begin{array}{l}\text { Reemplaza } \\
\text { vehículos con } \\
\text { ruedas y aviones. }\end{array}$ & $\begin{array}{l}\text { Aumenta } \\
\text { el uso de } \\
\text { energía. }\end{array}$ & $\begin{array}{l}\text { Satisface la } \\
\text { necesidad de } \\
\text { transportarse } \\
\text { con rapidez. }\end{array}$ & Física \\
\hline $\begin{array}{l}\text { Vehículos para } \\
\text { viajes } \\
\text { interplanetarios }\end{array}$ & $\begin{array}{l}\text { Sirve para viajar } \\
\text { a otros } \\
\text { planetas. }\end{array}$ & $\begin{array}{l}\text { Movilidad } \\
\text { interplanetaria }\end{array}$ & $\begin{array}{l}\text { Remplaza cohetes } \\
\text { espaciales. }\end{array}$ & $\begin{array}{l}\text { Aumenta } \\
\text { el uso de } \\
\text { energía. }\end{array}$ & $\begin{array}{l}\text { Satisface la } \\
\text { necesidad de } \\
\text { transportarse } \\
\text { con rapidez. }\end{array}$ & Física \\
\hline Transbordadores & $\begin{array}{l}\text { Sirve para } \\
\text { transportarse } \\
\text { de un lugar a } \\
\text { otro. }\end{array}$ & Movilidad rápida & $\begin{array}{l}\text { Reemplaza } \\
\text { vehículos con } \\
\text { ruedas y aviones. }\end{array}$ & $\begin{array}{l}\text { Aumenta } \\
\text { el uso de } \\
\text { energía. }\end{array}$ & $\begin{array}{l}\text { Satisface la } \\
\text { necesidad de } \\
\text { transportarse } \\
\text { con rapidez. }\end{array}$ & Física \\
\hline Paredovisor & $\begin{array}{l}\text { Sirve para } \\
\text { proyectar } \\
\text { imágenes. }\end{array}$ & Entretenimiento & $\begin{array}{l}\text { Reemplaza a las } \\
\text { televisiones de } \\
\text { leds. }\end{array}$ & $\begin{array}{l}\text { Aumenta } \\
\text { el uso de } \\
\text { energía. }\end{array}$ & $\begin{array}{l}\text { Satisface la } \\
\text { necesidad de } \\
\text { adaptar las } \\
\text { imágenes en } \\
\text { cualquier } \\
\text { pared. }\end{array}$ & Física \\
\hline Mini fono & $\begin{array}{l}\text { Sirve para } \\
\text { comunicarse }\end{array}$ & Comunicación & $\begin{array}{l}\text { Remplaza al } \\
\text { celular y su corta } \\
\text { duración de la } \\
\text { batería. }\end{array}$ & $\begin{array}{l}\text { Aumenta } \\
\text { el uso de } \\
\text { energía. }\end{array}$ & $\begin{array}{l}\text { Satisface la } \\
\text { necesidad de } \\
\text { comunicación } \\
\text { y de no tener } \\
\text { que cargarlo } \\
\text { tan pronto } \\
\text { por su batería } \\
\text { de } 96 \text { horas }\end{array}$ & Física \\
\hline
\end{tabular}




\begin{tabular}{|c|c|c|c|c|c|c|}
\hline & & & & & de duración. & \\
\hline $\begin{array}{l}\text { Divisor } \\
\text { hologramático }\end{array}$ & $\begin{array}{l}\text { Sirve para } \\
\text { proteger las } \\
\text { ventanas. }\end{array}$ & $\begin{array}{l}\text { Protección del } \\
\text { exterior en los } \\
\text { edificios. }\end{array}$ & $\begin{array}{l}\text { Remplaza las } \\
\text { cortinas de tela. }\end{array}$ & $\begin{array}{l}\text { Aumenta } \\
\text { el uso de } \\
\text { energía. }\end{array}$ & $\begin{array}{l}\text { Satisface la } \\
\text { necesidad } \\
\text { estética y de } \\
\text { protegerse de } \\
\text { la luz exterior. }\end{array}$ & Física \\
\hline $\begin{array}{l}\text { Biotecnología: } \\
\text { Tejido antisudor. }\end{array}$ & $\begin{array}{l}\text { Sirve para no } \\
\text { sudar. }\end{array}$ & Protección & $\begin{array}{l}\text { Disminuye la } \\
\text { sudoración. }\end{array}$ & $\begin{array}{l}\text { Suprime } \\
\text { la } \\
\text { sudoració } \\
\text { n natural } \\
\text { del } \\
\text { cuerpo. }\end{array}$ & $\begin{array}{l}\text { Satisface la } \\
\text { necesidad de } \\
\text { no sudar. }\end{array}$ & Física \\
\hline Trajes atérmicos & $\begin{array}{l}\text { Sirve para } \\
\text { soportar las } \\
\text { fuertes } \\
\text { temperaturas } \\
\text { del exterior. }\end{array}$ & Protección & No se presenta & $\begin{array}{l}\text { No se } \\
\text { presenta }\end{array}$ & $\begin{array}{l}\text { Satisface la } \\
\text { necesidad de } \\
\text { protección en } \\
\text { un ambiente } \\
\text { extremadame } \\
\text { nte caliente. }\end{array}$ & Física \\
\hline Flash constante & $\begin{array}{l}\text { Sirve para } \\
\text { iluminar en lo } \\
\text { oscuro. }\end{array}$ & Iluminación & $\begin{array}{l}\text { Reemplaza las } \\
\text { linternas y } \\
\text { lámparas de } \\
\text { mano. }\end{array}$ & $\begin{array}{l}\text { Minimiza } \\
\text { el uso de } \\
\text { energía y } \\
\text { baterías. }\end{array}$ & $\begin{array}{l}\text { Satisface la } \\
\text { necesidad de } \\
\text { iluminar en } \\
\text { un contexto } \\
\text { en el que se } \\
\text { ha ido la } \\
\text { energía. }\end{array}$ & Física \\
\hline $\begin{array}{l}\text { Compartimentos de } \\
\text { exterminio }\end{array}$ & Sirve para jugar. & $\begin{array}{l}\text { Diversión a partir } \\
\text { de la violencia. }\end{array}$ & $\begin{array}{l}\text { Reemplaza las } \\
\text { consolas de video } \\
\text { juegos. }\end{array}$ & $\begin{array}{l}\text { No se } \\
\text { presenta }\end{array}$ & $\begin{array}{l}\text { Satisface la } \\
\text { necesidad de } \\
\text { divertirse. }\end{array}$ & $\begin{array}{l}\text { Virtualida } \\
\text { d }\end{array}$ \\
\hline $\begin{array}{l}\text { Cerraduras } \\
\text { inteligentes }\end{array}$ & $\begin{array}{l}\text { Sirven para } \\
\text { cerrar puertas. }\end{array}$ & Seguridad & $\begin{array}{l}\text { Remplaza } \\
\text { cerraduras que se } \\
\text { abren con llaves. }\end{array}$ & $\begin{array}{l}\text { Aumenta } \\
\text { el uso de } \\
\text { energía. }\end{array}$ & $\begin{array}{l}\text { Satisface la } \\
\text { necesidad de } \\
\text { sentirse } \\
\text { seguro. }\end{array}$ & Física \\
\hline $\begin{array}{l}\text { Red de agua pública } \\
\text { (funciona con } \\
\text { energía nueva) }\end{array}$ & $\begin{array}{l}\text { Sirve para } \\
\text { suministrar } \\
\text { agua a los }\end{array}$ & $\begin{array}{l}\text { Medio para } \\
\text { obtener agua }\end{array}$ & $\begin{array}{l}\text { Remplaza la } \\
\text { tubería que } \\
\text { funciona por }\end{array}$ & $\begin{array}{l}\text { Aumenta } \\
\text { el uso de } \\
\text { energía. }\end{array}$ & $\begin{array}{l}\text { Satisface las } \\
\text { necesidades } \\
\text { básicas que se }\end{array}$ & Física \\
\hline
\end{tabular}




\begin{tabular}{|l|l|l|l|l|l|l|}
\hline & edificios. & & presión. & $\begin{array}{l}\text { obtienen con } \\
\text { el agua. }\end{array}$ & \\
\hline $\begin{array}{l}\text { Procesador de } \\
\text { basura }\end{array}$ & $\begin{array}{l}\text { Sirve para } \\
\text { descomponer } \\
\text { basura. }\end{array}$ & $\begin{array}{l}\text { Medio para } \\
\text { desechar basura. }\end{array}$ & $\begin{array}{l}\text { Remplaza los } \\
\text { botes de basura y } \\
\text { los basureros. }\end{array}$ & $\begin{array}{l}\text { Aumenta } \\
\text { el uso de } \\
\text { energía. }\end{array}$ & $\begin{array}{l}\text { Satisface la } \\
\text { necesidad de } \\
\text { desechar los } \\
\text { residuos que } \\
\text { no se } \\
\text { necesitan. }\end{array}$ \\
\hline
\end{tabular}

Fuente: Elaboración propia

\section{La nueva y la vieja tecnología}

En el texto se presentan dos tipos de tecnología: La nueva y la vieja (así denominadas en el propio texto), esta última considerada ya obsoleta, digna ya sólo de un museo de antigüedades. Se expresa una oposición entre estos dos tipos de tecnología a lo largo del cuento. La tecnología vieja se ha conservado gracias a la insistencia de Hellit (pareja del protagonista y narrador de la historia, Wilfred), quien también aparece descrito como amante de las novedades tecnológicas.

A continuación, se presenta una descripción y comparación entre estos dos tipos de tecnología según el texto:

Tabla 2. Nueva y vieja tecnología.

\begin{tabular}{|l|l|}
\hline NUEVA TECNOLOGÍA & VIEJA TECNOLOGÍA \\
\hline $\begin{array}{l}\text { Cortina de defensa: Es una especie de capa } \\
\text { que protege al planeta (no se describe en el } \\
\text { texto). }\end{array}$ & $\begin{array}{l}\text { No presenta correspondiente ni se } \\
\text { menciona. }\end{array}$ \\
\hline $\begin{array}{l}\text { Circulador de moléculas: Mantiene la } \\
\text { temperatura interna de los edificios } \\
\text { (viviendas, comercios, edificios, empresas). }\end{array}$ & También llamado equipo de frío-calor. \\
Se interrumpió abruptamente tras la el desván junto con otros objetos \\
obsoletos. Pesa poco. Necesita de los
\end{tabular}




\begin{tabular}{|c|c|}
\hline $\begin{array}{l}\text { invasión de los purpurados, por lo que } \\
\text { ahora está a oscuras su tablero. } \\
\text { Se instalaron circuladores masivamente. }\end{array}$ & $\begin{array}{l}\text { antiguos enchufes. Aún funciona y se fija } \\
\text { su temperatura a dieciocho grados. } \\
\text { Produce un chorro de aire fresco. Al } \\
\text { funcionar produce un zumbido. }\end{array}$ \\
\hline $\begin{array}{l}\text { Activador de flujo de neones: Genera luz, } \\
\text { los invasores interrumpieron el suministro. }\end{array}$ & $\begin{array}{l}\text { Vieja instalación eléctrica: Opera en modo } \\
\text { suplementario. Los invasores no se } \\
\text { molestaron en interrumpir ese suministro. } \\
\text { Sólo el tres por ciento de la población } \\
\text { conserva la electricidad. } \\
\text { Solo sirve para iluminación si se } \\
\text { mantienen las viejas luminarias, es } \\
\text { incompatible con el resto de aparatos } \\
\text { (nuevos) y es muy caro su costo mensual. }\end{array}$ \\
\hline $\begin{array}{l}\text { Nuevas fuentes energéticas: } \\
\text {-Flujo de neones (sin energía no corre fluido } \\
\text { por las cañerías) que forma parte de una } \\
\text { red general. }\end{array}$ & Electricidad. \\
\hline Servicio público de teletransportación. & $\begin{array}{l}\text { No presenta correspondiente ni se } \\
\text { menciona. }\end{array}$ \\
\hline Nuevos transportadores (no se describen) & $\begin{array}{l}\text { No presenta correspondiente ni se } \\
\text { menciona. }\end{array}$ \\
\hline $\begin{array}{l}\text { Vehículos (no se describen) pero se utilizan } \\
\text { para viajes interplanetarios. }\end{array}$ & $\begin{array}{l}\text { No presenta correspondiente ni } \\
\text { menciona. }\end{array}$ \\
\hline $\begin{array}{l}\text { Transbordadores (se mencionan pero no se } \\
\text { describen). }\end{array}$ & $\begin{array}{l}\text { No presenta correspondiente ni se } \\
\text { menciona. }\end{array}$ \\
\hline Adaptable & \\
\hline
\end{tabular}




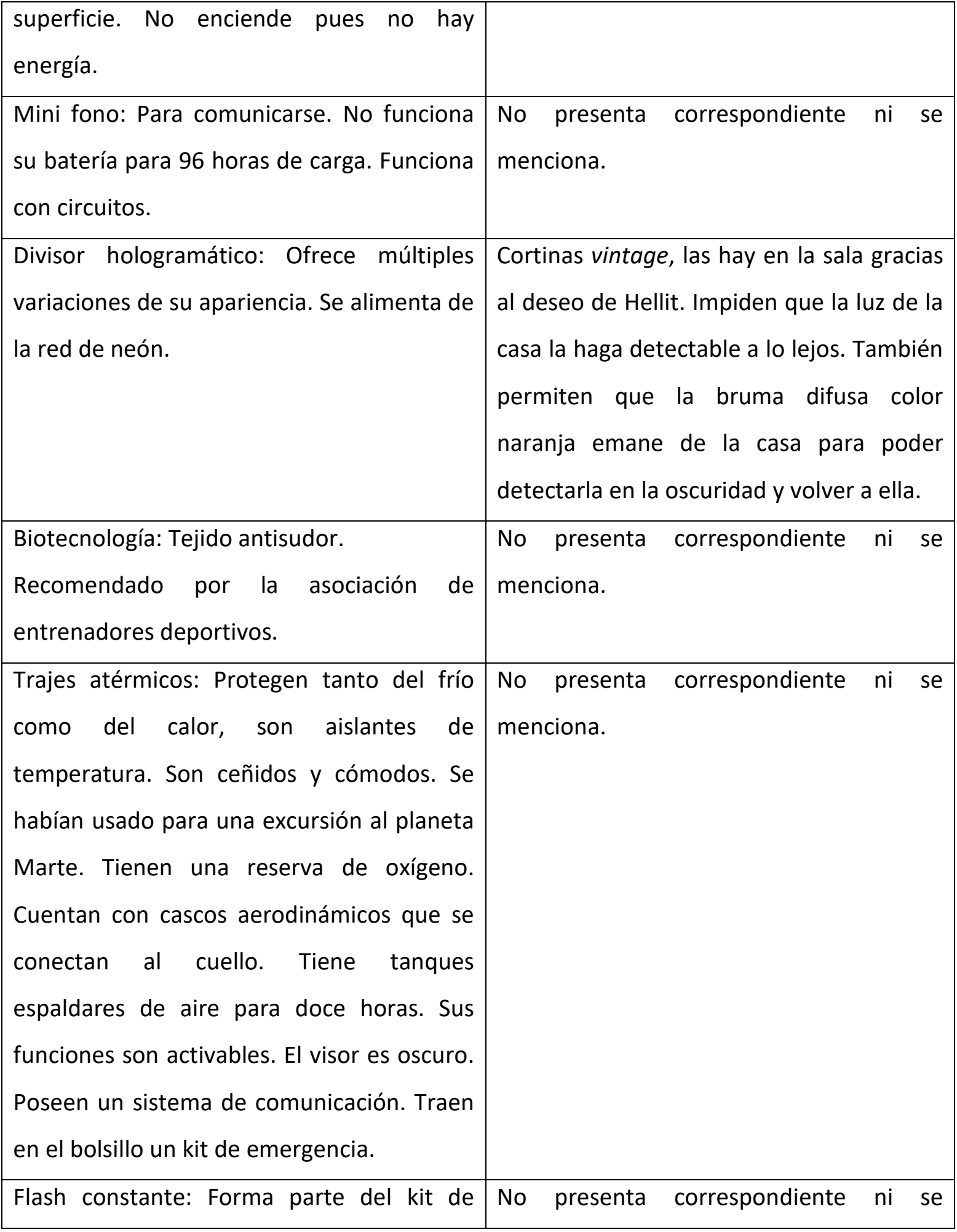




\begin{tabular}{|c|c|}
\hline $\begin{array}{l}\text { emergencia de los trajes atérmicos. Tiene el } \\
\text { tamaño de un dedo pero abre un cono de } \\
\text { luz poderoso con un mínimo consumo de } \\
\text { baterías. }\end{array}$ & menciona. \\
\hline $\begin{array}{l}\text { Compartimentos de exterminio: Tipo de } \\
\text { juego al que son afectos las nuevas } \\
\text { generaciones del siglo XXII. }\end{array}$ & $\begin{array}{l}\text { No presenta correspondiente ni se } \\
\text { menciona. }\end{array}$ \\
\hline Cerraduras inteligentes. & $\begin{array}{l}\text { No presenta correspondiente ni se } \\
\text { menciona. }\end{array}$ \\
\hline Red de agua pública (funciona con energía). & $\begin{array}{l}\text { Bidones de agua: Almacenados por } \\
\text { aquellos que todavía conservan la } \\
\text { costumbre de hacerlo. }\end{array}$ \\
\hline $\begin{array}{l}\text { Procesador de basura: Hace tratable } \\
\text { ecológicamente todo desecho de basura, } \\
\text { incluso bolsas (no se especifica si son de } \\
\text { plástico). }\end{array}$ & $\begin{array}{l}\text { No presenta correspondiente ni se } \\
\text { menciona. }\end{array}$ \\
\hline
\end{tabular}

Fuente: Elaboración propia.

El texto contrapone la tecnología nueva con la vieja, la cual es denominada obsoleta. Sin embargo, la tecnología vieja tiene la función de salvarles la vida a los personajes y se considera suerte no haberse desecho de ella:

1. El aire acondicionado permite controlar la temperatura a dieciocho grados en la sala, en contraposición de la temperatura imperante en el medio que es de setenta grados Celsius. Los personajes sufren de una deshidratación extrema y tanto el ambiente como el piso arden, respirar quema. Este control de la temperatura generado por el obsoleto equipo de aire acondicionado se percibe esperanzador, vital: 
a) El zumbido del aparato de aire acondicionado suena como "[...] la melodía más bella del universo, interpretada por una orquesta seleccionada entre los grandes músicos de la historia." (Goñi, 2018, p. 61)

b) A pesar de que el circulador de moléculas no funciona y la temperatura no autorregula la casa el aire acondicionado se percibe como el "[...] equipo que nos ha devuelto la esperanza [...]" (p. 63).

c) La temperatura de setenta grados deshidrata extremadamente a los personajes, de modo que el aire frío que sale del aire acondicionado se percibe como "[...] la corriente fresca que en este instante es el símbolo de la vida" (p. 65).

d) Hellit ha conservado aparatos obsoletos con la loca idea de montar un museo de antigüedades, por lo que Wilfred ahora lo concibe como la "[...] locura que me ha salvado la vida" (p. 68).

e) Wilfred, al final del cuento, ha cambiado su percepción del equipo de aire acondicionado: "Pilar me guiña un ojo, está sin traje, encargada de custodiar nuestra arma principal: el equipo de aire acondicionado que nos mantendrá vivos en las batallas" (p. 68).

2. La vieja electricidad permitió a algunos de los personajes tener luz, pues las nuevas energías dejaron de funcionar. El ambiente se describe oscuro, incluso en la calle Wilfred afirma que no podrían regresar a casa sin la luz anaranjada que escapaba por las cortinas: "Permiten que una difusa bruma naranja emane de la sala [...]" (p. 63).

3. Las cortinas, que ya han sido sustituidas en el siglo XXII por los divisores hologramáticos, permiten que haya luz sin que les permita ser detectados por los purpurados: "[...] las cortinas de Hellit impiden que la casa sea un faro detectable a lo lejos [...]" (p. 63).

4. Los bidones de agua les permiten acceder al líquido vital pues la red de agua pública no funciona. Estos bidones los tienen debido a que algunos conservaban la vieja costumbre de almacenarlos. 
5. Los supervivientes encuentran en la casa de un hombre llamado el loco, carcajes, flechas y ballestas para defenderse de los invasores.

En el texto, lo nuevo y lo viejo se conjugan para que se reúna un equipo de supervivientes. La nueva tecnología le sirve a Wilfred y su hermana Edith para buscarlos y encontrarlos en las casas vecinas y en el argento súper:

1. Utilizan los trajes atérmicos para sobrevivir a un exterior hostil a una temperatura de setenta grados Celsius y buscar a personas que aún estuvieran vivas, para llevarlas a su casa.

2. El flash constante le permite ver en la oscuridad para buscar supervivientes.

3. Las viejas tecnologías permiten que la casa de Wilfred y Edith se convierta en la base donde terminan reunidos los supervivientes de la zona, en total 9 personas.

Las nuevas tecnologías también se utilizan en el siglo XXII con fines decorativos:

1. Árboles ornamentales (interrumpen la iluminación estelar): Parecen obstaculizar la búsqueda de supervivientes que realizan Wilfred y Edith, pues bloquean la escasa luz estelar. El entorno es oscuro y lleno de penumbras.

2. Divisor hologramático que ofrece diversas apariencias: Ya no funciona pues su energía depende de la red de neón, la cual ya no está activa.

3. Anocheceres diseñados para beber martinis en el jardín: se mencionan en el texto, pero no se indica si aún funcionan o no.

Sólo hay un tipo de biotecnología que se menciona en el cuento: Los tejidos antisudor de Edith, que no han servido ante un calor tan extremo, pues Edith inconsciente tiene la ropa que se adhiere a ella por lo mojada que se encuentra. Este tipo de tecnología es ficcional, pero podría estar contemplada por Rueda-López (2007) en su artículo "La tecnología en la sociedad del siglo XXI: Albores de una nueva revolución industrial" (p. 2), donde menciona como una de las futuras tecnologías:

Ingeniería inyectable de tejidos (Injectable Tissue Engineering): Para sustituir a los tradicionales transplantes de órganos, se está a punto de aplicar un método por el que se 
inyecta articulaciones con mezclas diseñadas de polímeros, células y estimuladores de crecimiento que solidifiquen y formen tejidos sanos (p. 2).

Wilfred afirma que este tipo de tejido antisudor de nada ha servido, pues Edith también está empapada de sudor, deshidratándose debido a la alta temperatura del medio que los rodea.

En el cuento, las nuevas tecnologías son utilizadas cotidianamente para fines recreativos como:

1. Una excursión de trekking a Marte.

2. Un crucero a los anillos de Saturno.

A pesar de que constantemente se utiliza en el texto el adjetivo "obsoleta" para denominar a la vieja tecnología, un equipo que forma parte de ésta terminará siendo el elemento más importante para lograr la supervivencia de los personajes: El equipo de aire acondicionado (que a su vez opera con la fuente de energía obsoleta: Electricidad). Su importancia llega a tal punto, que el título del cuento "La máquina de respirar" se refiere a él, pues respirar el aire caliente a setenta grados es muy difícil, el aire arde y quema. El equipo de aire acondicionado adquiere los siguientes simbolismos en el texto:

1. Esperanza

2. Símbolo de la vida

3. Arma principal para mantenerse con vida entre batallas

4. Su zumbido es asimilado a la melodía más bella del universo

Con ello se puede resumir que la percepción de este ha cambiado de máquina obsoleta a una síntesis de esperanza, vida y belleza. En la oposición tecnología nueva vs tecnología vieja, se superpone la vieja, porque es la que sirve para sobrevivir. A pesar de cuanto haya avanzado el desarrollo tecnológico en el siglo XXII, se deja en claro que las necesidades básicas del ser humano siguen siendo las mismas:

1. Agua: mantenerse hidratado 
2. Cierta temperatura ambiental: 18 grados (en el texto, la temperatura perfecta para Wilfred).

3. Ambiente respirable

4. Oxigeno (en los tanques espaldares para poder respirar fuera de casa)

5. Luz

6. Alimento

7. Medio de defensa: armas

Cinco de estas necesidades básicas necesarias para la supervivencia en el ambiente post apocalíptico que plantea el texto son cubiertas por la vieja tecnología: Bidones de agua, aire acondicionado, energía eléctrica, ballestas y sus flechas.

\section{Los invasores y la tecnología terrestre nueva y vieja}

En el cuento, la Tierra ha sido invadida y atacada por una raza alienígena: Los purpurados, con los que los terrícolas habían ya tenido un mal encuentro en el planeta Xircón. Los purpurados presentan las siguientes características:

1. Muy inteligentes

2. Aptos para vivir en el ambiente terrestre

3. Antropomorfos

4. Débiles

5. Se matan fácilmente

6. Frágiles

Los purpurados han sido lo suficientemente inteligentes como para destruir y desactivar las tecnologías vitales de los terrícolas con la intención de adueñarse del planeta:

1. Superaron la cortina de defensa del planeta tierra.

2. Desconectan la red de neón y dejan sin energía el planeta tierra, no hay luz y no funciona ningún aparato, ni los de comunicación como el mini fono. 
3. Interrumpieron el circulador de moléculas, que mantiene la temperatura de los edificios, por lo cual la temperatura sube a 70 grados.

4. Cortan la red de agua pública, de la que se abastecen las personas para beber.

Los purpurados son entonces capaces de destruir o desactivar las nuevas tecnologías terrestres. A pesar de ser tan frágiles físicamente, su inteligencia les ha permitido montar un escenario de muerte en la tierra, pues solo la energía eléctrica, ya obsoleta para la mayoría y que solo conserva un tres por ciento de la población terrestre, funciona. Además, se hace necesario también haber conservado un equipo de aire acondicionado para controlar la temperatura y generar un ambiente respirable. En palabras del protagonista del cuento Wilfred:

Son extremadamente frágiles, aunque inteligentes y aptos para vivir en el ambiente terrestre. Tan inteligentes que averiguaron el punto débil de nuestra cómoda sociedad y nos atacaron donde no pudimos defendernos. Y ahí están los débiles, los frágiles, haciéndonos hervir, matándonos como si hicieran huevos duros de la manera en que los hacía mi abuela, superviviente del siglo XXI. (Goñi, 2018, p. 62).

Los purpurados han puesto fin a las nuevas tecnologías, pero nunca pensaron en desactivar las viejas. No las tomaron en consideración y, gracias a ello, un puñado de seres humanos logra sobrevivir. Los seres humanos son, por mucho, más fuertes físicamente que los purpurados. Un pequeño grupo de seres humanos puede acabar con cientos de purpurados debido a su fragilidad. Se pueden matar fácilmente como afirma Wilfred. Este hecho genera esperanza en el texto para el lector, para los personajes del cuento la esperanza es la máquina de respirar: El equipo de aire acondicionado.

Los purpurados están cerca, pues diez objetos extraños azulados sobrevolaban la ciudad y Carlos, uno de los supervivientes, los vio descender en la plaza. Los terrícolas están listos para la batalla, preparados con viejas tecnologías principalmente. De las nuevas tecnologías, los trajes atérmicos son los que les permitirán librar batalla en las calles y cuentan con pistolas eléctricas y el 
flash constante les permitirá ver en la oscuridad. Las viejas tecnologías les aportan a los supervivientes: agua, energía, la máquina de respirar (el arma secreta: el equipo de aire acondicionado) y ballestas con sus respectivas flechas.

No se menciona con qué tecnología cuentan los purpurados, además de los objetos extraños en los que vuelan. Se presenta así, en el texto, un escenario post apocalíptico para la guerra entre dos especies inteligentes que dominan diferentes tecnologías.

\section{El cuerpo}

En el texto se presentan dos visiones sobre el cuerpo. La primera visión es una visión sobre el cuerpo propio y la segunda es una visión sobre el cuerpo del otro. El cuerpo propio es expresado la mayoría de las veces a partir de las funciones de una determinada parte del cuerpo y de cómo estas partes son descritas.

En el texto se hace énfasis en las funciones del cuerpo y sus partes como se muestra en la tabla que aparece a continuación:

Tabla 3. Funciones y descripciones del cuerpo

\begin{tabular}{|c|c|c|}
\hline $\begin{array}{c}\text { Parte o } \\
\text { acción del } \\
\text { organismo }\end{array}$ & Referencia en el texto & Función, proceso, estado o percepción \\
\hline Respiración & $\begin{array}{l}\text { "Respiro. Es la primera } \\
\text { advertencia que recibe } \\
\text { mi conciencia" (Goñi, } \\
2018, \text { p. } 55 \text { ) }\end{array}$ & $\begin{array}{l}\text { Función respiratoria. La advertencia es una } \\
\text { señal que va en relación con el primer atisbo } \\
\text { de vida. }\end{array}$ \\
\hline Nariz & $\begin{array}{l}\text { "La nariz está en su } \\
\text { sitio, el aire que la }\end{array}$ & $\begin{array}{l}\text { Función respiratoria: Se indica que el aire pasa } \\
\text { por ella, como por un lugar, pues la acción es }\end{array}$ \\
\hline
\end{tabular}




\begin{tabular}{|c|c|c|}
\hline & $\begin{array}{ll}\text { atraviesa } & \text { parece } \\
\text { quemarme" } & \text { (Goñi, } \\
\text { 2018, p. 55) } & \end{array}$ & $\begin{array}{l}\text { "atravesar". } \\
\text { Ubicación de una parte del cuerpo: Se expresa } \\
\text { la posibilidad de que la nariz se encuentre en } \\
\text { otra parte. } \\
\text { Se refiere a la nariz en tercera persona, lo que } \\
\text { da idea de que la nariz puede no ser parte de } \\
\text { su cuerpo. No se utiliza el adjetivo "mi" para } \\
\text { referirse a ella, aunque la narración es en } \\
\text { primera persona. }\end{array}$ \\
\hline Ojos & $\begin{array}{l}\text { "Puedo abrir los ojos. Y } \\
\text { ver" (Goñi, 2018, p. } \\
\text { 55). }\end{array}$ & $\begin{array}{l}\text { Función: Ver. } \\
\text { El verbo poder hace que la acción de ver se } \\
\text { convierta en la posibilidad de que pudiera o no } \\
\text { suceder. }\end{array}$ \\
\hline Cuerpo & $\begin{array}{l}\text { "Siento mi cuerpo, mis } \\
\text { extremidades, estoy } \\
\text { completo" (Goñi, 2018, } \\
\text { p. 55). }\end{array}$ & $\begin{array}{l}\text { Estado: Bienestar. } \\
\text { Percepción: Completitud corporal. } \\
\text { Esta frase puede ser una simple enunciación } \\
\text { de la comprobación de su estado de bienestar } \\
\text { después de las explosiones, pero la forma en } \\
\text { que se expresa denota la toma de consciencia } \\
\text { del sujeto como unidad completa. }\end{array}$ \\
\hline Sudor & $\begin{array}{l}\text { "Me noto ensopado, el } \\
\text { cabello empapado, la } \\
\text { espalda" (Goñi, 2018, } \\
\text { p. 55). }\end{array}$ & $\begin{array}{l}\text { Proceso: deshidratación extrema que sufre el } \\
\text { sujeto. } \\
\text { Percepción: Por medio de verbos que expresan } \\
\text { exceso de agua en el exterior del cuerpo. }\end{array}$ \\
\hline $\begin{array}{l}\text { Palma de la } \\
\text { mano }\end{array}$ & $\begin{array}{l}\text { "Arriesgo un leve } \\
\text { movimiento, mi palma }\end{array}$ & $\begin{array}{l}\text { Proceso: Contacto con el entorno. } \\
\text { Función: Tocar. }\end{array}$ \\
\hline
\end{tabular}




\begin{tabular}{|c|c|c|}
\hline & $\begin{array}{l}\text { derecha entra en } \\
\text { contacto con el piso de } \\
\text { la sala" (Goñi, 2018, p. } \\
\text { 55). }\end{array}$ & $\begin{array}{l}\text { El adjetivo posesivo "mi" describe la mano } \\
\text { como propia del narrador, pero la acción que } \\
\text { realiza con ella lo hace en tercera persona. }\end{array}$ \\
\hline Sangre & $\begin{array}{l}\text { "Dejo que la sangre } \\
\text { circule, que el cuerpo } \\
\text { se acostumbre" (Goñi, } \\
2018, \text { p. } 55 \text { ). }\end{array}$ & $\begin{array}{l}\text { Función: Circulación. } \\
\text { Percepción: Acostumbrarse. Da la impresión } \\
\text { de que la función se hubiera detenido durante } \\
\text { el desmayo. } \\
\text { El verbo "dejar" puede hacer alusión a que el } \\
\text { sujeto pueda ser capaz de regular la } \\
\text { circulación, pero también a que debe estar } \\
\text { quieto para que la circulación vuelva a la } \\
\text { normalidad después del desmayo. }\end{array}$ \\
\hline Consciencia & $\begin{array}{l}\text { "Suficiente rato me ha } \\
\text { dado para ubicarme en } \\
\text { tiempo y lugar, debo } \\
\text { reaccionar" (Goñi, } \\
\text { 2018, p. 55). }\end{array}$ & $\begin{array}{l}\text { Función: Reacción. } \\
\text { Esta descripción hace alusión a la } \\
\text { desorientación que ha sufrido el cuerpo tras el } \\
\text { desmayo, pero el sujeto se vuelve consciente } \\
\text { del retardo. }\end{array}$ \\
\hline $\begin{array}{l}\text { Boca } \\
\text { aparato } \\
\text { fonatorio }\end{array}$ & $\begin{array}{l}\text { "Trato de hablar, tengo } \\
\text { la boca reseca, } \\
\text { articulo, pero no emito } \\
\text { sonidos" (Goñi, 2018, } \\
\text { p. 55). }\end{array}$ & $\begin{array}{l}\text { Estado: Deshidratación. } \\
\text { Función: Del habla. } \\
\text { Hay incapacidad de ejercer la función del } \\
\text { habla. }\end{array}$ \\
\hline $\begin{array}{l}\text { Manos } \\
\text { Tronco } \\
\text { Cabeza }\end{array}$ & $\begin{array}{l}\text { "Apoyo las manos, } \\
\text { primero debo erguir el } \\
\text { tronco y luego la }\end{array}$ & $\begin{array}{l}\text { Proceso: Levantar la parte superior del cuerpo. } \\
\text { Intervienen tres partes del cuerpo. } \\
\text { Se describe el proceso en tres etapas. }\end{array}$ \\
\hline
\end{tabular}




\begin{tabular}{|c|c|c|}
\hline & $\begin{array}{l}\text { cabeza" (Goñi, 2018, p. } \\
55 \text { ). }\end{array}$ & \\
\hline $\begin{array}{l}\text { Consciencia } \\
\text { Sudor }\end{array}$ & $\begin{array}{l}\text { "Me obligo a } \\
\text { abandonar el divague, } \\
\text { sudo con profusión" } \\
\text { (Goñi, 2018, p. 56). }\end{array}$ & $\begin{array}{l}\text { Función: Concentración. } \\
\text { Proceso: Deshidratación. } \\
\text { Mente confundida todavía, cuerpo en proceso } \\
\text { de deshidratación. }\end{array}$ \\
\hline Sentido & $\begin{array}{l}\text { "Me siento estable, } \\
\text { puedo ponerme de } \\
\text { pie" (Goñi, 2018, p. } \\
56) .\end{array}$ & $\begin{array}{l}\text { Función: Ponerse de pie. } \\
\text { Estado: Estabilidad. } \\
\text { Proceso: Erguirse. }\end{array}$ \\
\hline Saliva & $\begin{array}{l}\text { "Recupero saliva” } \\
\text { (Goñi, 2018, p. 56). }\end{array}$ & $\begin{array}{l}\text { Proceso: Producción de saliva de forma } \\
\text { consciente. }\end{array}$ \\
\hline Comer & $\begin{array}{l}\text { "Tomo unas fetas de } \\
\text { fiambre, para agregar } \\
\text { sal al organismo" } \\
\text { (Goñi, 2018, p. 56). }\end{array}$ & $\begin{array}{l}\text { Función: Alimentación. } \\
\text { Proceso: Agregar sal al organismo. } \\
\text { Acción para conservar líquido en el cuerpo. }\end{array}$ \\
\hline $\begin{array}{l}\text { Sentido } \\
\text { auditivo } \\
\text { mente }\end{array}$ & $\begin{array}{l}\text { "Reparo en un detalle: } \\
\text { el silencio" (Goñi, } \\
\text { 2018, p. 56). }\end{array}$ & $\begin{array}{l}\text { Función: Escuchar. } \\
\text { Estado: Atención. } \\
\text { Se activa el sentido del oído. }\end{array}$ \\
\hline Toser & $\begin{array}{l}\text { "Me da tos }[\ldots] " \text { (Goñi, } \\
2018, \text { p. 57). }\end{array}$ & Función: Reaccionar ante la resequedad. \\
\hline
\end{tabular}

Fuente: Elaboración propia 
En el texto se pueden encontrar variados aspectos de las partes del cuerpo, pero son las funciones las que aparecen como principal característica del cuerpo del narrador. También es posible observar que en varias frases parece haber una conceptualización del cuerpo como máquina. Claro que la comparación nunca es hecha explícitamente, pero bastaría observar las funciones que se describen para darse cuenta de que el cuerpo humano, al igual que una máquina, puede enviar señales, realizar procesos, estabilizarse, dejar charcos en el piso, activarse, ejecutar una idea, repetir y organizar datos, arrancar y gastar energía.

Conforme ha avanzado la ciencia y la tecnología, el ser humano se ha tenido que enfrentar a una nueva realidad y para ello ha debido crear un nuevo lenguaje con el que nombrar esa nueva realidad. Pero no es solo que el ser humano haya tenido que crear un nuevo lenguaje para nombrar los avances de la ciencia y la tecnología, sino que también ha tenido que adaptarse a las herramientas que de ellas se han creado, porque la tecnología ha hecho que una tarea se vuelva más sencilla de realizar y eso forzosamente ha tenido que reestructurar la forma de concebir la cotidianidad de las sociedades a lo largo del tiempo. Floralba Aguilar Gordón señala que "Las tecnologías no son independientes de la cultura, integran con ella un sistema sociotécnico inseparable" (2011, p. 155).

De esa forma, el ser humano convierte a la tecnología en parte fundamental de su día a día y eso en algún momento hace que haya una dependencia entre cuerpo y herramienta. Pero esa unión entre cuerpo y herramienta no es física. La tecnología se añade como otro elemento más a la cultura y hay formas de apropiarse de ella mediante el lenguaje. En este texto no hay herramientas a las que parezca haber una dependencia, es decir, no hay una concepción de la herramienta como extensión del cuerpo. El lenguaje que la cultura ha creado para nombrar una realidad a la que se han insertado los avances de la ciencia y tecnología hace que tarde o temprano ese mismo lenguaje se utilice para el cuerpo humano, porque ya no es solo el hecho de que la tecnología funcione externamente para facilitar una tarea mecánica, sino que los avances de la ciencia y tecnología han servido para manipular e introducirse en el cuerpo del ser humano, sea esto para mejorar o no la vida del ser humano. La dependencia existe en relación con los aparatos y máquinas del entorno, 
pero el narrador de este texto no las percibe ni describe como parte de su cuerpo, sino que es su cuerpo mismo el que parece funcionar como una máquina.

Solo relacionando el discurso tecnológico con la configuración del cuerpo propio en este texto se puede entender la metáfora del cuerpo como máquina. La situación que se narra en el texto es la que permite describir gran parte de las funciones que se describen. La historia del cuento es adecuada porque hace que en torno a ella se tenga que recurrir a la descripción de una persona que debe recuperarse de un desmayo producido por una gran explosión que es similar al apagón que sufre un aparato eléctrico. De la misma forma que todos los aparatos se apagaron después de la explosión, el propio narrador dice "mi mundo se volvió súbitamente negro y caí en la nada" (Goñi, 2018, p. 55). Esto solo tiene sentido cuando se lee en el texto la preocupación que se tiene por recuperar, mantener y no gastar energía, al igual que un aparato eléctrico indispensable. Se describe el despertar del cuerpo a través de varias frases que involucran varios sentidos y procesos. Dentro de este despertar se va narrando la recuperación de su cuerpo hasta conseguir estar estable:

1) Recupera la respiración y siente el aire caliente.

2) Recupera la vista.

3) Puede sentir las sensaciones.

4) Espera a que la sangre vuelva a circular.

5) Espera un momento para reubicarse en lugar y tiempo.

6) Recupera cierta movilidad, pero todavía no puede emitir sonidos con la boca.

7) Siente cierta estabilidad.

8) Recupera saliva.

9) Ingiere alimento para recuperar sal (ha oído que la sal retiene líquidos).

10) Se percata de lo que escucha.

11) Busca agua, porque va dejando charcos en el piso. 
De los procesos que se describen para recuperar la estabilidad, solo algunos pueden verdaderamente detenerse tras la pérdida de la conciencia y otros que siguen realizándose pero que no pueden detenerse porque eso equivaldría a morir. De esa forma, esto puede catalogarse como el reinicio de una máquina que lo que ocupa es recuperar algo de energía y obtener algo de agua para volver a funcionar. Es claro que durante un desmayo todos los sentidos se apagan y no funcionan sino hasta que el sujeto se despierta.

\section{Las funciones del cuerpo}

Las funciones de ver, oír, sentir, degustar y oler solo se pueden detener cuando una persona se muere, duerme o se desmaya, esta última situación es a la que se somete el personaje llamado Wilfred. Por otra parte, parece que la respiración y la circulación de la sangre son procesos que se vuelven conscientes, es decir, como si Wilfred pudiera regularlos. Esto parece ser así si se toman literalmente las frases que lo expresan. La respiración se produce por la señal que recibe su conciencia. ¿Pero de dónde recibe esa señal? Si se supone que es la propia conciencia la que debería emitirla. En este caso, parece que hay una separación entre cuerpo y mente y el que emite las señales es el cuerpo y el que las recibe es la consciencia. Entre cuerpo y mente, ¿quién o qué es Wilfred?, ¿mente o cuerpo o cuerpo y mente? Esta separación explicaría la posterior descripción de algunas partes del cuerpo y sus funciones en tercera persona, lo que da una idea de que no son parte de Wilfred porque él es solo la conciencia. Pero, aunque haya este atisbo de separación entre cuerpo y mente al inicio del texto, posteriormente y tras recuperar todas las funciones y sentidos se vuelven inconscientes, vuelve a funcionar con normalidad su cuerpo.

Esta primera parte del cuento contiene un intertexto de Descartes con su famosa frase "Pienso, luego existo", pero el narrador cuestiona el resultado de pensar, porque no es el pensamiento el que da la idea de la existencia, sino el acto de respirar. Pero se puede entender mejor por qué se utiliza esta frase puesta en duda si se cita un fragmento de Descartes de Meditaciones Metafísicas: 
Y aun cuando, acaso, o más bien, ciertamente, como luego diré, tengo yo un cuerpo al que estoy estrechamente unido, sin embargo, puesto que por una parte tengo una idea clara y distinta de mí mismo, según la cual soy algo que piensa y no extenso y, por otra parte, tengo una idea distinta del cuerpo, según la cual este es una cosa extensa, que no piensa, resulta cierto que yo, es decir, mi alma, por la cual soy lo que soy, es entera y verdaderamente distinta de mi cuerpo, pudiendo ser y existir sin el cuerpo (Descartes, 2007, p. 178-179).

No es literalmente que Descartes diga que el cuerpo y el alma están divididas, sino que existe una percepción sobre el cuerpo que permite pensar que pueden separarse. Descartes plantea que el alma puede existir sin el cuerpo (en el ser humano) y el cuerpo puede existir sin el alma (en los animales). Lo que plantearía el cuento, entonces, al poner la frase "Respiro. Es la primera advertencia que recibe mi conciencia... ¡Pienso!, luego ¿existo?” (Goñi, 2018, p. 55), sería la de cierta incapacidad de separar alma y cuerpo. De esa forma, aunque Descartes afirme que la conciencia pueda existir sin el cuerpo, para Wilfred poder pensar no es suficiente para existir, pues parece considerar la existencia como la correlación entre cuerpo y alma o conciencia. La conciencia está atada al cuerpo, no puede separarse de él, y por lo tanto la conciencia es parte de los elementos que el cuerpo humano necesita para desempeñar una vida normal.

\section{El cuerpo como máquina}

Descartes es uno de los primeros pensadores que ha dejado por escrito la concepción del cuerpo humano como máquina, autor al que el cuento hace referencia. El principal objetivo de Descartes, al menos en la quinta parte de Discurso del Método, era refutar la no creencia de Dios mediante el análisis y posterior conclusión de la complejidad del cuerpo. Él estableció que no podía existir un cuerpo que en apariencia pudiera ser como el ser humano, puesto que Dios (o la Naturaleza), habrían elaborado al ser humano con dos características incapaces de ser creadas por el propio ser humano: 1) La lengua y 2) La razón. Lo que resulta interesante de esta quinta parte es la forma en 
que Descartes va describiendo las funciones del cuerpo y se encuentran frases como "[...] fábrica de los nervios y de los músculos del cuerpo humano" (Descartes, 2006, p. 65) y "[...] autómatas o máquinas movientes" (p. 66) que permiten pensar el cuerpo humano como una máquina.

En el cuento se utilizan algunas frases que circundan alrededor de la energía, que serviría para argumentar aún más la idea del cuerpo como máquina. Aparece el agua metaforizada como energía. Si se pierde agua (sudor) se pierde energía o si se hidrata entonces se gana energía. A continuación, se muestra una tabla con las frases encontradas en el texto que hacen alusión a la percepción del cuerpo como máquina:

Tabla 4. Percepción del cuerpo como máquina.

\begin{tabular}{|c|c|}
\hline Frase & Percepción del cuerpo como máquina \\
\hline $\begin{array}{l}\text { "Preciso más agua, voy dejando en el suelo un } \\
\text { charco al caminar" (Goñi, 2018, p. 57). }\end{array}$ & $\begin{array}{l}\text { El verbo "precisar" disocia al agua para } \\
\text { ser entendida como necesidad humana. } \\
\text { Se trata de un verbo que se utiliza para lo } \\
\text { que requiere una máquina y no un } \\
\text { cuerpo. }\end{array}$ \\
\hline $\begin{array}{l}\text { “Ojalá que le dure la energía, esa que se nos } \\
\text { escapa por los poros de la piel” (Goñi, 2018, p. 60). }\end{array}$ & $\begin{array}{l}\text { El agua, en forma de sudor, se percibe } \\
\text { como energía. El sudor está siendo } \\
\text { expresado en términos de energía. El } \\
\text { agua dentro del cuerpo es definida como } \\
\text { energía. }\end{array}$ \\
\hline “Dejamos de chorrear” (Goñi, 2018, p. 60). & $\begin{array}{l}\text { Dejan de tirar agua igual a dejan de tirar } \\
\text { energía. "Chorrear" es otro verbo } \\
\text { asociado a máquinas y no a seres } \\
\text { humanos. }\end{array}$ \\
\hline
\end{tabular}




\begin{tabular}{|c|c|}
\hline $\begin{array}{l}\text { “Edith se activa y ejecuta una buena idea” (Goñi, } \\
2018 \text {, p. 61). }\end{array}$ & $\begin{array}{l}\text { Después de que Edith se recupera de la } \\
\text { deshidratación, Wilfred describe la forma } \\
\text { en cómo ella se activa. Esta frase, por los } \\
\text { verbos "activar" y "ejecutar", hace que se } \\
\text { piense en Edith como una máquina. }\end{array}$ \\
\hline $\begin{array}{l}\text { “Hay algunos datos más que me repito mientras } \\
\text { ordeno mis pensamientos" (Goñi, 2018, p. 62). }\end{array}$ & $\begin{array}{l}\text { Esta frase describe una forma más en la } \\
\text { que podría entenderse la forma en que } \\
\text { funciona la memoria, como si la mente } \\
\text { fuese una computadora, en la que se } \\
\text { introducen datos (pensamientos e ideas) } \\
\text { para organizarlas. }\end{array}$ \\
\hline $\begin{array}{l}\text { “Arrancamos a caminar, despacio para conservar } \\
\text { energías" (Goñi, 2018, p. 63). }\end{array}$ & $\begin{array}{l}\text { El verbo "arrancar" se utiliza con } \\
\text { máquinas cuando comienzan a funcionar } \\
\text { o desplazarse. } \\
\text { La velocidad, en el contexto del cuento, } \\
\text { es negativa, porque gasta energía. }\end{array}$ \\
\hline $\begin{array}{l}\text { “Esperemos, cuanto menos oxígeno gastemos, } \\
\text { mejor” (Goñi, 2018, p. 68). }\end{array}$ & $\begin{array}{l}\text { El oxígeno es expresado como algo que } \\
\text { "se gasta", como lo haría una máquina, } \\
\text { en términos de un consumible. }\end{array}$ \\
\hline
\end{tabular}

Fuente: Elaboración propia.

Las frases expuestas en la tabla ya no se centran en los sentidos, ni en la respiración ni en la circulación de la sangre. Estas frases se relacionan con los pensamientos y la importancia de ahorrar energía. Los pensamientos se catalogan por Wilfred como datos que se ejecutan y organizan. La frase que enuncia Wilfred con relación a su hermana muestra muy claramente que el cuerpo funciona como una máquina. El concepto de energía, por otra parte, es esencial en la configuración del cuerpo. Desde que se crearon las primeras herramientas, tales como un palo para golpear o una 
piedra para cortar, la energía la suministraba el cuerpo que la utilizaba. Con la llegada de la revolución industrial, se observa ya no solo la fuerza producida por los cuerpos humanos, sino también la energía que produce el carbón. Hasta ese momento, había solo dos energías, una que producía el ser humano y otra que era obtenida mediante la quema del carbón. Hasta el día de hoy se pueden contabilizar más energías y la que siempre ha estado presente es la electricidad, que es suministrada en máquinas o en aparatos eléctricos. Pero no es el hecho de que la energía humana haya estado siempre presente la que genera el discurso de la importancia de ahorrarla, sino la importancia que se le ha dado a la energía en un mundo en el que gran parte de la vida depende de ella como lo es, en el texto, en el siglo XXII. El texto expresa que sin energía nada funciona, ni siquiera el cuerpo humano, es por eso que dada la situación post apocalíptica a la que se enfrentan sea todavía de mayor importancia que la sepan reservar y utilizar adecuadamente.

Para entender mejor la relación entre los conceptos de agua y energía se puede citar la teoría de Lakoff y Johnson (2009), quienes establecen que la metáfora conceptual permite estructurar un concepto en términos de otro. Esta relación de conceptos surgió desde el paradigma científico y posteriormente se ha ido culturalizando, ya que los científicos, para poder expresar la estructura, función y características de la electricidad, tomaron como base el concepto de lo líquido para estructurar el concepto de la electricidad. Esto puede verse en frases como "corriente eléctrica", "corriente continua", "corriente directa", "corriente alterna", entre otras. Desde esta conceptualización de la energía, estructurada en parte en términos de lo líquido, es que puede entenderse la manera en que funciona el concepto de energía dentro del cuento, en donde lo líquido, si se pierde, es sinónimo de perder energía.

\section{Referencias}

Aguilar, F. (2011). Reflexiones filosóficas sobre la tecnología y sus nuevos escenarios. Sophia, Colección de Filosofía de la Educación, núm. 11, 123-174.

Descartes, R. (2006). Discurso del método. España: Ediciones Folio.

Descartes, R. (2007). Meditaciones metafísicas. España: Austral. 
Goñi, J. (2018). La máquina de respirar. Líneas de cambio, Antología de ciencia ficción latinoamericana, 55-68.

Lakoff, G. y Johnson, M. (2009). Metáforas de la vida cotidiana (10 므. $)$. España: Cátedra.

Rueda, J. (2007). La tecnología en la sociedad del siglo XXI: Albores de una nueva revolución industrial. Aposta. Revista de Ciencias Sociales, núm. 32, 1-28.

Solivérez, C. (2003). Educación Tecnológica para comprender el fenómeno tecnológico. Buenos Aires: Instituto Nacional de Educación Técnica. 